\title{
Major gene effects on apolipoprotein B concentrations in families of adolescents-Results from a community-based study in Taiwan
}

\author{
Kuo-Liong Chien ${ }^{\text {a,b }}$, Wei J. Chen ${ }^{\text {c,d,* }}$, Hsiu-Ching Hsu ${ }^{\text {b }}$, Ta-Chen $\mathrm{Su}^{\mathrm{b}}$, \\ Ming-Fong Chen ${ }^{\mathrm{b}}$, Yuan-Teh Lee ${ }^{\mathrm{b}}$ \\ a Institute of Preventive Medicine, College of Public Health, National Taiwan University, Taiwan \\ ${ }^{\mathrm{b}}$ Department of Internal Medicine, National Taiwan University Hospital, Taiwan \\ ${ }^{\mathrm{c}}$ Department of Psychiatry, National Taiwan University Hospital, Taiwan \\ ${ }^{\mathrm{d}}$ Institute of Epidemiology, College of Public Health, National Taiwan University, Taiwan
}

Received 13 March 2005; received in revised form 17 August 2005; accepted 18 August 2005

Available online 17 October 2005

\begin{abstract}
Background: Apolipoprotein (Apo) B is considered as a risk factor for atherosclerosis. Previous reports of segregation analyses on the mode of inheritance of Apo B were inconsistent because of heterogeneity in study population or elderly adult diseased probands. We performed complex segregation analysis of Apo B levels in the families of adolescents, systematically ascertained from junior high school students in a rural community in Taiwan.

Results: There is a sex-specific influence in the variation of apo B levels. The mother-daughter (0.216), sister-sister (0.181), sister-brother (0.179) correlations were higher than father-son (0.206), brother-brother (0.002) or cross-sex correlations for the variation in Apo B levels. By the variance component model, the heritability estimate was $26.3 \pm 6.7 \%(P<.0001)$ in Apo B levels. Commingling analysis indicated that a 2-component distribution was needed to account for Apo B variation. Segregation analysis using regressive models revealed that the best-fit model of Apo B was the model of major gene effect plus familial correlation. The gene frequency controlling high Apo B was 0.17, and 3 means of genotypes were $56.3,54,2$, and $117.2 \mathrm{mg} / \mathrm{dl}$.

Conclusion: Variations of Apo B levels in the normal range among adolescent families are controlled by major gene, and further identification of this gene locus will be mandatory.
\end{abstract}

(C) 2005 Elsevier B.V. All rights reserved.

Keywords: Apolipoprotein B; Heritability; Major genes; Community study

\section{Introduction}

Apolipoprotein (Apo) B is a risk factor for coronary heart disease and its concentration is related with high low density lipoprotein (LDL) cholesterol levels [1]. Mechanisms of controlling Apo B concentrations were complex and involved multiple gene effects. Among hypercholesterolemia patients, Apo B gene and other genes such LDL

* Corresponding author. Institute of Epidemiology, College of Public Health, National Taiwan University, No. 1, Ren-Ai Road, Taipei, Taiwan 100. Tel.: +886 223123456x8360; fax: +886 223519736 .

E-mail address: weijen@ha.mc.ntu.edu.tw (W.J. Chen). receptor were reported to have synergistic effects controlling Apo B and LDL-C concentrations [2,3]; e.g., the codon 3531 mutation of Apo B could enhace the LDL receptor gene mutation to facilitate hyperlipidemia effects [4]. In general population, the mechanisms of controlling Apo B concentrations might be more complex. It is important to determine if major gene effects exists in controlling Apo B concencentration. Major gene effects can be revealed by complex segregation analysis (CSA) for Apo B concentrations, and is important for subsequent gene localization [5]. Even if some major susceptibility genes are already identified, CSA can help shed light on whether other genes exist [6]. 
So far, studies of CSA on Apo B and LDL-cholesterol concentrations have been conducted mainly in families of clinical patients and population-based non-clinical adults, with conflicting findings reported [7-16]. First, families of probands from familial hypercholesterolemia or hyperlipidemic clinics tended to support the existence of major gene effect in high risk hyperlipidemic families $[12,15]$, but in later study, Bredie et al. demonstrated that only environmental model was fitted in families with familial combined hyperlipidemia [9]. Second, families of probands who underwent cardiac angiography failed to discrminate which model is better [10], while families with acute myocardial infarction were reported to have major gene effect $[7,13]$. Finally, population from Utah families or healthy volunteers in community can be identified with major gene effects controlling Apo B [11,16].

Two reasons for these inconsistent results are possible. First, since clinical diseases such as familial combined hyperlipidemia or coronary heart diseases have a variety of etiologies, ascertaining probands under these clinical conditions would likely lead to etiological heterogeneity. Second, adult probands' Apo B concentrations might be subjected to various environmental exposure and hence obscure the major gene effects. One way to overcome these limitations is to conduct CSA in families of younger subjects who do not have clinical symptoms and are systematically recruited. In this study we employed the approach to recruit young probands and their first-degree relatives from a Taiwanese rural community. The study aimed to assess the possible mechanisms of genetic contribution to Apo B concentrations through a series of family-genetic analyses, including familial correlation, commingling analysis, and CSA.

\section{Materials and methods}

\subsection{Subjects}

This family study was part of the Chin-San Community Cardiovascular Study, a prospective cohort study began in 1990 [1,17]. The family study project started in 1997 and was designed to recruit probands from students in the only junior high school in the community [18]. Briefly, a total of 1063 students (response rate 94.6\%) agreed to participate in a general health check-up after informed consent was obtained. They underwent examinations for anthropometric measures, blood pressure, and lipid profiles. Seven measures, including total cholesterol, triglyceride, low density lipoprotein (LDL) cholesterol, body mass index, systolic pressure, diastolic pressure, and high density lipoprotein (HDL) cholesterol were collected. The high-risk young probands were defined as the highest scores of above seven measures, which were 90th percentile values among all subjects $(n=171)$. The control young probands were ascertained by random sampling of other young students $(n=197)$. Because the original stratification was not based exclusively on the Apo B and the results of CSA for the families of the two proband groups were similar, only the results of all families together with correction for ascertainment on proband's Apo B were reported in this study. After obtaining informed consent from probands' family members, the same measures were performed for each family member. Only first-degree relatives were included for this genetic study, with a total of 1145 subjects.

\subsection{Measures of lipid profiles}

The measurement of various lipid profiles has been described in detail elsewhere [19]. Briefly, a blood sample of $20 \mathrm{ml}$ was drawn from each participant after a 12-h overnight fast. Enzymatic methods were used to determine serum cholesterol and triglyceride (Merck 14354 and 14366, respectively). If the triglyceride concentration was $>400$ $\mathrm{mg} / \mathrm{dl}$, cholesterol and apolipoprotein were measured from infranate density $>1.006 \mathrm{~kg} / \mathrm{l}$ from ultracentrifugation [20]. Apo B concentrations were measured by turbidimetric immunoassay (Sigma, St. Louis, MO) [21]. The standard samples for apolipoprotein assay were from the Center for Disease Control, Atlanta, GA. The coefficient of variation of Apo B measured in our laboratory was $<3 \%$. If extreme values were found, repeated measures were done for confirmation. All measures were performed in July and August, and hence seasonal variation could be minimized.

\subsection{Statistical analysis}

The basic characteristics of Apo B and related traits were specified by proband and family status. We adjusted a person's Apo B concentrations for known determinants by regressing for age, age $^{2}$, gender, age* gender, age ${ }^{2 *}$ gender, body mass index, smoking and alcohol drinking status. Residual values plus the sample mean of Apo B (55.7 mg/ dl) were then used for the following analyses.

\subsection{Commingling and familial correlation studies}

Distributions of the Apo B concentration among the study subjects were fitted under normal distribution assumption. Commingling analysis was performed on standardized Apo $B$ values to test whether the data were best described by 1,2 , or 3 more normal distributions by ADMIX program [22]. The parameters for each component's mean, variance and proportion were estimated by the maximal likelihood method. The best-fitted distribution model was selected by comparing the likelihood ratio test statistics among different nested models. The intra-familial correlation coefficients of Apo B trait were measured in different pairs, including spouse, parent-offspring, and siblings, by FCOR program in SAGE [23]. We compared 2 correlation coefficients of parent-offspring pairs by the Fisher's $z$ test. Heritability estimate of Apo B concentrations in the families were 
estimated by the variance component model, which was implemented in the SOLAR software [24].

\subsection{Complex segregation analyses}

The inheritance mode of complex trait was analyzed by complex segregation analysis. Segregation analysis of Apo B levels was conducted using regressive models as implemented in the REGC program of SAGE release 3.1 $[23,25]$. These models assume that variation of Apo B concentration among family members is the result of a major gene effect, polygenes, and residual nongenetic effects. First, the presence of a major gene is assessed by allowing two factors or alleles (A and $\mathrm{B}$ ) at a single locus, resulting in three 'ousiotypes' in individuals (AA, AB, BB). The means of Apo $\mathrm{B}$ for each ousiotype is denoted $\mu_{\mathrm{AA}}$, $\mu_{\mathrm{AB}}, \mu_{\mathrm{BB}}$, with one common variance of $\sigma^{2}$. The frequencies of allele A and B are denoted $\mathrm{q}_{\mathrm{A}}$ and $\left(1-\mathrm{q}_{\mathrm{A}}\right)$, respectively. Individuals of each type are assumed to transmit allele $\mathrm{A}$ to their offspring with transmission probabilities $\tau_{\mathrm{AA}}, \tau_{\mathrm{AB}}$ and $\tau_{\mathrm{BB}}$, respectively. In classical Mendelian models, $\tau_{\mathrm{AA}}, \tau_{\mathrm{AB}}$ and $\tau_{\mathrm{BB}}$ is $1,0.5$, and 0 . Second, the correlation between spouses, mother and offspring, father and offspring, and between siblings, are denoted $\rho_{\mathrm{MF}}, \rho_{\mathrm{MO}}, \rho_{\mathrm{FO}}$, and $\rho_{\mathrm{SS}}$, and presented as polygenes effects.

The analyses started with fitting a general model, in which all parameters were estimated. Then we compared the general model with various submodels in which certain parameters were restricted to specific values. Under a Mendelian model, the transmission probabilities, $\tau_{\mathrm{AA}}, \tau_{\mathrm{AB}}$ and $\tau_{\mathrm{BB}}$, were held equal to Mendelian expectation of $1,0.5$, and 0 . A nontransmitted environmental effect model predicts that the probability that an individual has 1 ousiotype or another is independent of both the person's generation and the ousiotypes of his/her parents. The fit of nested models is compared with the likelihood ratio test, calculated as -2 of the difference between the ln likelihood of the models being compared. The likelihood ratio value follows a chi-square distribution, with degrees of freedom equal to the difference between the models in the number of parameters estimated. Among nonhierarchical models, the most parsimonious model is that with the lowest values of Akaike's information criterion (AIC $=-2$ ln likelihood $+2[-$ number of estimated parameters]) [26].

We used the adjusted Apo B values without logarithm transformation for the segregation analysis because normalizing transformation of a biologically skewed trait would decrease power to detect a major gene effect when one exists [27]. Instead, we fit the environmental effect in the model selection. If such a model can be rejected, the major gene effect will not be due to skewness of the residual Apo B levels [28]. Ascertainment correction was conducted by conditioning the phenotypes of probands since families in this study were selected through high risk and control probands.

\section{Results}

\subsection{Descriptive data}

There were 368 probands, 333 siblings and 444 parents in this study. All subjects had average body fatness (mean body mass index values of 20 in the probands and siblings, and 24 in the parents) (Table 1). The parents had higher total cholesterol, HDL and LDL cholesterol profiles, and higher smoking and drinking rates than the probands and siblings. In addition, the parents had larger standard deviations in lipid profiles, especially in triglyceride, than their offspring. The values of skewness and kurtosis showed that Apo B and triglyceride values were not normally distributed among the parent group. Proportion of Apo B variation in this sample explained by gender, age, age ${ }^{2}$, gender*age, gender*age ${ }^{2}$, body mass index, smoking and drinking habits was up to $30.8 \%$.

Table 1

Basic demographic and atherosclerotic risk profiles in this family study, specified by generations $(n=1145)$

\begin{tabular}{|c|c|c|c|c|c|c|c|c|c|c|c|c|}
\hline & \multicolumn{4}{|c|}{ Proband $(N=368)$} & \multicolumn{4}{|c|}{ Siblings $(N=333)$} & \multicolumn{4}{|c|}{ Parents $(N=444)$} \\
\hline & Mean & SD & Skewness & Kurtosis & Mean & SD & Skewness & Kurtosis & Mean & SD & Skewness & Kurtosis \\
\hline $\operatorname{Age}(\mathrm{y})^{* * *}$ & 16.45 & 0.97 & 0.33 & 0.34 & 17.83 & 3.43 & 0.59 & 1.05 & 43.65 & 5.74 & 1.35 & 4.65 \\
\hline Body weight $(\mathrm{kg})^{* * *}$ & 54.07 & 12.87 & 1.04 & 1.48 & 52.57 & 11.03 & 0.93 & 52.54 & 62.87 & 11.93 & 1.08 & 6.02 \\
\hline Body height $(\mathrm{cm})$ & 161.28 & 8.46 & -0.06 & 0.03 & 161.27 & 8.95 & -0.01 & 1.06 & 160.90 & 7.68 & 0.07 & -0.31 \\
\hline Body mass index $\left(\mathrm{kg} / \mathrm{m}^{2}\right)^{* * *}$ & 20.63 & 3.87 & 1.13 & 1.24 & 20.08 & 3.13 & 1.31 & 4.26 & 24.23 & 3.91 & 1.03 & 4.40 \\
\hline Total cholesterol $(\mathrm{mg} / \mathrm{dl}) * * *$ & 168.98 & 36.43 & 1.78 & 11.91 & 164.94 & 33.17 & 0.74 & 0.70 & 195.85 & 35.76 & 0.29 & 0.54 \\
\hline Triglyceride $(\mathrm{mg} / \mathrm{dl}) * * *$ & 85.49 & 40.14 & 1.92 & 7.98 & 88.86 & 43.67 & 2.96 & 18.43 & 156.24 & 134.29 & 2.66 & 8.26 \\
\hline HDL-C (mg/dl)* & 43.49 & 10.44 & 0.50 & 0.23 & 44.21 & 9.55 & 0.46 & 0.07 & 42.26 & 11.02 & 0.72 & 0.77 \\
\hline LDL-C (mg/dl)*** & 79.67 & 32.08 & 0.61 & 0.33 & 86.24 & 35.61 & 1.35 & 4.74 & 122.13 & 36.22 & 0.26 & 0.61 \\
\hline Aро B (md/dl)*** & 46.76 & 13.39 & 0.35 & 1.80 & 49.70 & 13.87 & 0.14 & 0.46 & 64.53 & 18.85 & 1.64 & 5.32 \\
\hline Smoking*** & $1(0.3 \%)$ & & & & $35(10.5 \%)$ & & & & $159(35.8 \%)$ & & & \\
\hline Alcohol drinking*** & $1(0.3 \%)$ & & & & $25(7.5 \%)$ & & & & $173(39.0 \%)$ & & & \\
\hline
\end{tabular}

$* P<0.05$ for the ANOVA test comparing the three groups.

*** $P<0.001$ for the ANOVA test comparing the three groups. 
Table 2

Familial correlation coefficients in residual Apo B levels in this family study by equal weight to pedigrees

\begin{tabular}{lcc}
\hline & Pairs \# & Correlation \\
\hline Spouse & 156 & 0.074 \\
Parental-offspring & 893 & 0.110 \\
Sibling & 450 & 0.125 \\
Mother-daughter & 240 & 0.216 \\
Mother-son & 216 & 0.206 \\
Father-daughter & 233 & 0.064 \\
Father-son & 204 & 0.032 \\
Sister-sister & 136 & 0.181 \\
Sister-brother & 221 & 0.179 \\
Brother-brother & 93 & 0.002
\end{tabular}

\subsection{Familal correlation, heritability and commingling results}

After adjustment for these nonlipid covariates, the correlation coefficients between residual Apo B concentrations among family members are displayed in Table 2 . The parental offspring and sibling correlation coefficients were relatively high ( 0.110 and 0.125 , respectively), and only minimal spouse correlation was found $(0.074)$. It is possible that there is a sex-specific influence in the variation of apo B levels in the family data. The mother-daughter $(0.216)$, sister-sister $(0.181)$, sister-brother $(0.179)$ correlations were higher than father-son $(-0.032)$, brotherbrother (0.002) for the variation in Apo B levels. The correlations of mother-son and father-son were significantly different $(0.206$ vs. $-0.032, P<0.05)$, and those of mother-daughter and father-daughter were borderline different $(0.216$ vs. $0.064, P=0.093)$. By the variance component model, the heritability estimate was $26.3 \% \pm$ $6.7 \%(P<.0001)$ in Apo B levels.

A 2-component rather than single-component distribution was the best-fit model in high risk and control groups, respectively. The component mean, variance, and proportions for the 2-component distribution for the high risk group were $(-0.07,4.60),(0.70,0.66)$, and $(98.6 \%, 1.4 \%)$, respectively. The $\chi^{2}$ for comparing the 2-component with 1 component distribution was $127.24(d f=3, p=0.001)$, while that for comparing the 2-component with 3 -component distribution was $2.36(d f=3, p=0.50)$. Similarly, the component mean, variance, and proportions for the 2component distribution for the control group were $(-0.07$, $3.6),(0.73,1.57)$, and $(98.1 \%, 1.9)$, respectively. The $\chi^{2}$ for comparing the 2-component with one component distribution was $93.92(d f=3, p=0.001)$, while that for comparing the 2-component with 3-component distribution was 0.35 $(d f=3, p=0.95)$. The finding of 2 component distributions is compatible with a major gene hypothesis. However, commingling may also arise through other causes. Thus, segregation analysis was used to determine whether these major effects segregated in families according to Mendelian expectations.

\subsection{Complex segregation analysis results}

The results of complex segregation analyses of Apo B are presented in Table 3 . The sporadic and the familial correlation models were rejected due to a $P$ value of each model's $\chi^{2}$ of $<0.001$. Among restricted model, the bestfitted model was the Mendelian model by the $\chi^{2}$ test $\left(\chi^{2}=7.76, d f=3, P=0.051\right)$ and lowest AIC value

Table 3

Parameter estimates from segregation analysis of residual Apo B levels: Class D regressive models, conditional on proband phenotypes

\begin{tabular}{|c|c|c|c|c|c|c|c|c|c|c|c|c|}
\hline \multirow[t]{2}{*}{ Model } & \multicolumn{2}{|l|}{ Sporadic } & \multicolumn{2}{|c|}{ Polygenes effect } & \multicolumn{2}{|c|}{$\begin{array}{l}\text { Environmental + familial } \\
\text { correlation }\end{array}$} & \multicolumn{2}{|c|}{$\begin{array}{l}\text { Mixed codominant } \\
\text { major gene effect }\end{array}$} & \multicolumn{2}{|c|}{$\begin{array}{l}\text { Mixed cultural } \\
\text { transmission }\end{array}$} & \multicolumn{2}{|c|}{$\begin{array}{l}\text { Unrestricted, } \\
\text { general }\end{array}$} \\
\hline & Parameter & S.E. & Parameter & S.E. & Parameter & S.E. & Parameter & S.E. & Parameter & S.E. & Parameter & S.E. \\
\hline $\mathrm{q}_{\mathrm{A}}$ & {$[1]$} & & {$[1]$} & & 0.855 & 0.019 & 0.829 & 0.025 & 0.831 & 0.025 & 0.983 & 0.005 \\
\hline$\tau_{\mathrm{AA}}$ & - & & - & & $=\mathrm{q}_{\mathrm{A}}$ & & {$[1]$} & & {$[1]$} & & 0.998 & 0.002 \\
\hline$\tau_{\mathrm{AB}}$ & - & & - & & $=\mathrm{q}_{\mathrm{A}}$ & & {$[0.5]$} & & {$[1]$} & & 1.000 & 0.000 \\
\hline$\tau_{\mathrm{BB}}$ & - & & - & & $=\mathrm{q}_{\mathrm{A}}$ & & {$[0]$} & & {$[0]$} & & 0.712 & 0.489 \\
\hline$\mu_{\mathrm{AA}}$ & 56.7 & 0.6 & 57.3 & 0.8 & 55.7 & 2.9 & 56.3 & 1.2 & 57.3 & 0.8 & 55.7 & 0.7 \\
\hline$\mu_{\mathrm{AB}}$ & $=\mu_{\mathrm{AA}}$ & & $=\mu_{\mathrm{AA}}$ & & 55.7 & 8.4 & 54.2 & 2.4 & 51.7 & 1.6 & 118.7 & 3.8 \\
\hline$\mu_{\mathrm{BB}}$ & $=\mu_{\mathrm{AA}}$ & & $=\mu_{\mathrm{AA}}$ & & 118.3 & 3.7 & 117.2 & 3.7 & 119.4 & 4.2 & 94.1 & 23.8 \\
\hline$\sigma^{2}$ & 248.5 & 13.2 & 255.4 & 15.4 & 167.4 & 9.7 & 166.2 & 9.9 & 178.1 & 10.6 & 167.4 & 9.9 \\
\hline$\rho_{\mathrm{MF}}$ & {$[0]$} & & 0.065 & 0.068 & 0.131 & 0.084 & 0.147 & 0.084 & 0.127 & 0.096 & 0.138 & 0.084 \\
\hline$\rho_{\mathrm{MO}}$ & {$[0]$} & & 0.279 & 0.058 & 0.267 & 0.048 & 0.270 & 0.048 & 0.284 & 0.050 & 0.263 & 0.048 \\
\hline$\rho_{\mathrm{FO}}$ & {$[0]$} & & 0.025 & 0.053 & 0.095 & 0.055 & 0.102 & 0.055 & 0.143 & 0.055 & 0.103 & 0.056 \\
\hline$\rho_{\mathrm{SS}}$ & {$[0]$} & & 0.219 & 0.071 & 0.154 & 0.048 & 0.150 & 0.048 & 0.136 & 0.046 & 0.152 & 0.047 \\
\hline \# & 2 & & 6 & & 9 & & 9 & & 9 & & 12 & \\
\hline$-2 \ln (\mathrm{L})$ & 5964.26 & & 5934.40 & & 5779.17 & & 5778.61 & & 5785.46 & & 5770.85 & \\
\hline AIC & 5968.26 & & 5946.40 & & 5797.17 & & 5796.61 & & 5803.46 & & 5794.85 & \\
\hline$\chi^{2}$ & 193.41 & & 163.6 & & 8.32 & & 7.76 & & 14.61 & & & \\
\hline$P$ & 0.000 & & 0.000 & & 0.040 & & 0.051 & & 0.002 & & Baseline & \\
\hline
\end{tabular}

Abbreviation: \#, number of parameters; SEM, standard error of mean; qA, gene frequency; $\tau \mathrm{AA}, \tau \mathrm{AB}, \tau \mathrm{BB}$, transmission probability; $\mu \mathrm{AA}, \mu \mathrm{AB}, \mu \mathrm{BB}$, genotype means; $\sigma^{2}$, variance; $\rho \mathrm{MF}, \rho \mathrm{MO}, \rho \mathrm{FO}, \rho \mathrm{SS}$, correlation coefficients among spouse, mother-offspring, father-offspring and sibling pairs; \#, number of parameters; $\ln (\mathrm{L})$, logarithm of likelihood; AIC, Akaike information criteria; $P$, significance level compared with the unrestricted general model. 
(5796.61). The environmental model was rejected, but the AIC values were just higher than Mendelian model $\left(\chi^{2}=8.32, d f=3, P=0.04, \mathrm{AIC}=5797.17\right)$. Further testing of mode of inheritance under the Mendelian model showed that codominant mixed major gene model is best fitted than dominant or recessive models $\left(\chi^{2}=139.92\right.$ and $\chi^{2}=33.64, d f=1$, both $P<0.001$ in dominant and recessive models, compared with codominant model, respectively). The gene frequency controlling low Apo B was 0.83, and three means of Apo B were 56.3, 54,2, and $117.2 \mathrm{mg} / \mathrm{dl}$, with common variance was 166.2. The mother-offspring correlation was higher than the father-offspring correlation (0.270 vs. 0.102$)$.

\section{Discussion}

This study showed that significant heritability and familial correlations of Apo B levels among young proband families and major genes were proven in segregation analyses results. This study have 2 scientific contributions. First, there is considerable homogeneity in this study population. Most of the subjects live in the same community, hence their social and living environments tended to be more similar than those in different communities. Second, the results are particularly relevant for a population at low risk for atherosclerosis, since the probands were systematically selected from young adolescents in the community.

Our results were consistent with those of previous familial correlation and commingling studies, which demonstrated that 2-component model explained Apo B well in familial combined hyperlipidemia patients [29]. We also demonstrated maternal-offspring correlations were significant and higher than faternal-offspring correlation. Also, the correlations of female siblings were higher than male siblings. It implied that maternal effects on offspring were more influential than paternal effects on controlling Apo B, and female roles had greater role in familial aggregation of Apo B concentrations [30]. Similarity in patterns of lifestyle and dietary habits among mother and offspring may explain high mother offspring correlations. Gender specificity was demonstrated in genomic control of complex trait in animal model [31].

From the segregation results, we clearly defined the gene frequency for high Apo B was 0.17, compatible with the commingling results and similar to studies on families of familial hypercholesterolemia [13], hyperlipidemic clinic [15], and healthy volunteers [16], which indicated that possible the same gene locus affected Apo B in different population. In our study, many individuals were still young and at low risk of cardiovascular disease. Several reasons may account for the major gene effect in these rather young population. First, the gene controlling Apo B level is prevalent in general population. Reports showed that Apo B concentrations were associated with various gene markers, especially in low density lipoprotein and other lipid metabolism enzymes, such as lipoprotein lipase, hepatic lipase and cholesterol ester transfer proteins [32,33]. Second, genetic factors controlling lipid levels were reported to have greater influences on young age than on older age [34]. So, it is feasible to find genetic components in young population. Although young adolescents were at lower risk of atherosclerosis, our study can still demonstrate major gene effects among young population.

The limitations of our study are the following. First, the one-locus model was assumed in the segregation analyses for complex trait. Complex trait such as Apo B concentration is controlled by multiple factors. Fortunately, simulation study demonstrated that one-locus model in complex segregation analysis has enough power to detect major gene effects in multiple-loci trait [35]. Second, epistasis among genes or gene-environmental interaction cannot be explored in this study. Incorporation with environmental factors can elucidate the possible roles of risk factors and interaction effects. The variation of serum levels of apo B is a complex trait and probably is influenced by effects of gene(s), environmental and their interactions. The presence or not of a major gene (or genes) in the studies populations reflect the balance of these effects. Besides "gene(s)", gene-environment interaction may have an important role in the variation of ApoB levels and be more prevalent in the adulthood. Finally, when measuring lipids in the $>1.006 \mathrm{~kg} / \mathrm{l}$ density fraction, it would exclude up to $5 \%$ of the true Apo B concentration in some cases, such as subjects with dysbetalipoproteinemia. Because the aim of this study was to investigate the inheritance mode of Apo B in general population, we would like to exclude the subjects with extreme high values of Apo B such as patients with dysbetalipoproteinemia. Also, we excluded the genetic dyslipidemia cases in our analysis.

In conclusion, we showed that there were significant mother-offspring correlation coefficients, significant heritability and major gene effects controlling Apo B. As the literatures showed that many candidate genes controlling lipid metabolism were related to Apo B concentrations, and our study results clearly demonstrated there existed major gene effects on controlling Apo B concentrations in general population, with the allele frequency as 0.17 . However, our present study did not show light on which gene markers is more suitable for further linkage analysis. Confirming the major gene effects, we can explore polymorphisms of possible candidate gene markers such as lipoprotein lipase and lipid-related metabolism enzymes with much confidence.

\section{Acknowledgement}

The authors wish to thank the staff of the Department of Cardiology, National Taiwan University Hospital, Taiwan, for their contributions and cooperation. The study was 
partially supported by National Science Council (NSC 902314-B-002-1983). Some of the results of this paper were obtained using the S.A.G.E. package of genetic epidemiology software, which is supported by a U.S. Public Health Service Resource Grant (RR03655) from the National Center for Research Resources.

\section{References}

[1] Chien KL, Sung FC, Hsu HC, Su TC, Lin RS, Lee YT. Apolipoprotein $\mathrm{A} 1$ and B, and stroke events in a community-based cohort in Taiwan: report of Chin-Shan community cardiovascular study. Stroke 2002;33: $39-44$.

[2] Coon H, Leppert MF, Kronenberg F, et al. Evidence for a major gene accounting for mild elevation in LDL cholesterol: the NHLBI Family Heart Study. Ann Hum Genet 1999;63:401-12.

[3] Haddad L, Day IN, Hunt S, Williams RR, Humphries SE, Hopkins PN. Evidence for a third genetic locus causing familial hypercholesterolemia. A non-LDLR, non-APOB kindred. J Lipid Res 1999;40:1113-22.

[4] Rabes JP, Varret M, Devillers M, et al. R3531C mutation in the apolipoprotein B gene is not sufficient to cause hypercholesterolemia. Arterioscler Thromb Vasc Biol 2000;20:E76-82.

[5] Jarvik GP. Complex segregation analyses: uses and limitations. Am J Hum Genet 1998;63:942-6.

[6] Cui J, Antoniou AC, Dite GS, et al. After BRCA1 and BRCA2 what is next? Multifactorial segregation analyses of three-generation, population-based Australian families affected by female breast cancer. Am J Hum Genet 2001;68:420-31.

[7] Amos CI, Elston RC, Srinivasan SR, et al. Linkage and segregation analyses of apolipoproteins A1 and B, and lipoprotein cholesterol levels in a large pedigree with excess coronary heart disease: the Bogalusa Heart Study. Genet Epidemiol 1987;4:115-28.

[8] Beaty TH, Prenger VL, Virgil DG, Lewis B, Kwiterovich PO, Bachorik PS. A genetic model for control of hypertriglyceridemia and apolipoprotein B levels in the Johns Hopkins colony of St. Thomas Hospital rabbits. Genetics 1992;132:1095-104.

[9] Bredie SJ, van Drongelen J, Kiemeney LA, Demacker PN, Beaty TH, Stalenhoef AF. Segregation analysis of plasma apolipoprotein B levels in familial combined hyperlipidemia. Arterioscler Thromb Vasc Biol 1997:17:834-40.

[10] Coresh J, Beaty TH, Kwiterovich POJ. Inheritance of plasma apolipoprotein B levels in families of patients undergoing coronary arteriography at an early age. Genet Epidemiol 1993;10:159-76.

[11] Hasstedt SJ, Wu L, Williams RR. Major locus inheritance of apolipoprotein B in Utah pedigrees. Genet Epidemiol 1987;4:67-76.

[12] Jarvik GP, Beaty TH, Gallagher PR, Coates PM, Cortner JA Genotype at a major locus with large effects on apolipoprotein B levels predicts familial combined hyperlipidemia. Genet Epidemiol 1993;10:257-70.

[13] Jarvik GP, Brunzell JD, Austin MA, Krauss RM, Motulsky AG, Wijsman E. Genetic predictors of FCHL in four large pedigrees. Influence of ApoB level major locus predicted genotype and LDL subclass phenotype. Arterioscler Thromb 1994:14:1687-94.

[14] Juo SH, Beaty TH, Kwiterovich POJ. Etiologic heterogeneity of hyperapobetalipoproteinemia (hyperapoB). Results from segregation analysis in families with premature coronary artery disease. Arterioscler Thromb Vasc Biol 1997;17:2729-36.
[15] Pairitz G, Davignon J, Mailloux H, Sing CF. Sources of interindividual variation in the quantitative levels of apolipoprotein $\mathrm{B}$ in pedigrees ascertained through a lipid clinic. Am J Hum Genet 1988;43:311-21.

[16] Tiret L, Steinmetz J, Herbeth B, et al. Familial resemblance of plasma apolipoprotein B: the Nancy study. Genet Epidemiol 1990;7:187-97.

[17] Lee YT, Lin RS, Sung FC, et al. Chin-Shan community cardiovascular cohort in Taiwan: baseline data and five-year follow-up morbidity and mortality. J Clin Epidemiol 2000;53:836-46.

[18] Chien KL, Hsu HC, Su TC, et al. Consistency in genetic inheritance mode and heritability patterns of triglyceride vs. high density lipoprotein cholesterol ratio in two Taiwanese family samples. BMC J Genet 2003;4:7-16.

[19] Chien KL, Lee YT, Sung FC, Hsu HC, Su TC, Lin RS. Hyperinsulinemia and related atherosclerotic risk factors in the population at cardiovascular risk: a community-based study. Clin Chem 1999;45: $838-46$.

[20] Warnick GR, Benderson J, Albers JJ. Dextran sulfate-Mg2+ precipitation procedure for quantitation of high-density-lipoprotein cholesterol. Clin Chem 1982;28:1379-88.

[21] Rifal N, King MC. Immunoturvidimetric assays of apolipoprotein A-I, A-II and B in serum. Clin Chem 1986;32:957-60.

[22] Cloninger CR, von Knorring L, Oreland L. Pentametric distribution of platelet monoamine oxidase activity. Psychiatr Res 1985;15:133-43.

[23] S.A.G.E. Statistical analysis for genetic epidemiology, Release 3.1. Computer program package available from the Department of Epidemiology and Biostatistics, Rammelkamp Center for Education and Research, MetroHelath Campus, Case Western Reserve.

[24] Almasy L, Blangero J. Multipoint quantitative-trait linkage analysis in general pedigrees. Am J Hum Genet 1998;62:1198-211.

[25] Chien KL, Yang CY, Lee YT. Major gene effects in systolic and diastolic blood pressure in the families receiving health examination in Taiwan. J Hypertens 2003;21:1-7.

[26] Akaike H. A new look at the statistical model identification. IEEE Trans Automat Contr 1974;AC-19:716-23.

[27] MacLean CJ, Morton NE, Lew R. Analysis of family resemblance. IV. Operational characteristics of segregation analysis. Am J Hum Genet $1975 ; 27: 365-84$.

[28] Demenais F, Lathrop M, Lalouel JM. Robustness and power of the unified model in the analysis of quantitative measurements. Am J Hum Genet 1986;38:228-34.

[29] Austin MA, Horowitz H, Wijsman E, Krauss RM, Brunzell J. Bimodality of plasma apolipoprotein B levels in familial combined hyperlipidemia. Atherosclerosis 1992;92:67-77.

[30] Namboodiri KK, Green PP, Kaplan EB, et al. Family aggregation of high density lipoprotein cholesterol. Collaborative lipid research clinics program family study. Arteriosclerosis 1983;3:616-26.

[31] Clark JS, Jeffs B, Davidson AO, et al. Quantitative trait loci in genetically hypertensive rats. Possible sex specificity. Hypertension 1996;28:898-906.

[32] Breslow JL. Human apolipoprotein molecular biology and genetic variation. Annu Rev Biochem 1985;54:699-727.

[33] Talmud PJ, Xu CF. Molecular biology of apolipoproteins: control of gene expression and structure-function relationship. In: Betteridge DJ, Illingworth DR, Shepherd J, editors. Lipoproteins in health and disease. London: Arnold Publisher; 1999. p. 181-97.

[34] Kovacs P, van den BJ, Kloting I. Effects of quantitative trait loci for lipid phenotypes in the rat are influenced by age. Clin Exp Pharmacol Physiol 1998;25:1004-7.

[35] Borecki IB, Province MA, Rao DC. Power of segregation analysis for detection of major gene effects on quantitative traits. Genet Epidemiol 1994;11:409-18. 